\title{
Automatic dual-axis solar tracker system design
}

\author{
Nurhani Amin ${ }^{1 *}$, Agustinus Kali ${ }^{1}$, Muchsin ${ }^{2}$, and Firman Syam ${ }^{1}$ \\ ${ }^{1}$ Departement of Electrical Engineering, Universitas Tadulako, 94118 Palu, Indonesia \\ ${ }^{2}$ Departement of Mechanical Engineering, Universitas Tadulako, 94118 Palu, Indonesia
}

\begin{abstract}
Sunlight is one of the energy that can be used to generate electricity. Converting solar energy into electrical energy required a device called Photo-Voltaic (PV). However, output of PV hardly depends on the position of PV to the sun. The maximum PV output will reach when the sun position perpendicular to the surface of PV. Therefore, the device that can track the position of $\mathrm{PV}$ is needed. The aim of this research is to design a track solar system using Arduino and LDR sensor to follow the sun movement. This method will be applied to a $80 \mathrm{Wp}$ solar panel. The output of the tracker solar system was compared to the fixed PV. The result shows that the output voltage of the tracker solar system reached $18.81 \mathrm{~V}$ that was higher than the fixed PV about $18,56 \mathrm{~V}$ and the output current of the tracker solar system reached 4,27 A that was higher than the fixed PV about 4,19 A.
\end{abstract}

\section{Introduction}

Human needs for energy continue to increase in daily life as a way to increase human potential that leads to social, economic and economic growth welfare and health. all people use energy to meet basic human needs such as lighting, cooking, comfort of space, mobility and communication and to serve productive processes. [1][2].

Renewable energy is all forms of energy both from the sun, geophysics or biological sources that can be quickly recovered by natural processes at the same level as or exceeding the level of their use. Renewable energy is obtained from recurrent energy flows that occur in the natural environment and includes resources such as biomass, solar energy, geothermal energy, hydropower, tides, and waves. [3][4] One of the renewable energy that has been developed in Indonesia is solar energy. The position of the sun and the position of the region on the surface of the earth have a real influence on the potential of solar energy in an area.

Palu City as the capital of Central Sulawesi Province is located in the Palu valley region and Palu Bay. This area consists of five dimensions, namely mountains, valleys, rivers, bays, and oceans. Astronomically, Palu City is between $0^{\circ}, 36^{\prime \prime}-0^{\circ}, 56^{\prime \prime}$ South Latitude and 119 $\circ, 45$ "- $121^{\circ}, 1$ " East Longitude, so that it is located exactly on the Equator with an altitude of 0-700 meters above sea level [5]. The geographic location of Palu City has the potential to receive high levels of sunlight. This condition is suitable for utilizing solar energy to produce electricity.

\footnotetext{
* Corresponding author : nhanie.lieben@gmail.com
} 
Solar energy is received by the earth in the form of solar radiation. The solar radiation consists of ultra-violet, visible and infrared radiation. The amount of solar radiation that reaches any location depends on several factors such as geographical location, time, season, the scope of land and local weather. The round shape of the earth causes sunlight that hits the earth's surface to have different angles ranging from $0^{\circ}$ to $90^{\circ}$. Maximum solar energy is received by the earth's surface when the position of sunlight is vertical. [6]

To convert solar energy into electrical energy an intermediary called a Photo-Voltaic (PV) is needed. However, in its application the position of the PV is static or does not move in the direction of the sun's rays even though the condition of the sun's energy can be optimized is when the PV position is upright with the sun. Therefore we need a tool that can follow the direction of sunlight so that it can optimize the performance of PV [7].

To maximize sunlight falling on the surface of the PV made a solar tracker. Research has been developed that applies a single-axis tracker [8-9] and a two-axis tracker [7] $\{10]$.

Stage of the research is.1. study Literature, in this section researchers look for material both in the library or on the internet to add references that support the research. 2. Selection of research sites, iIn this step the determination of the location of research in the area of Tadulako University. The research location is in the area of Electrical Engineering. 3. Prepare research tools, is the process of making research tools before doing research. 4. Initial measurement and observation, it is the process of taking initial data as a reference for conducting research and observations to see and determine the research location.5. Designing a solar direction detector on the solar cell trecker, the process of making or designing a solar direction detector on a solar cell trecker. 6. Measurement of data retrieval, this process is taking data from the direction of the solar detector on the solar cell trecker. 7. Data analysis, the data analysis process will be carried out after the field review process until the data collection process has been completed. The analysis is carried out on the solar panel tracking and the solar tracking microcontroller. In the solar panel tracking section includes PWM analysis (PWM input motor), light measurement (comparison of each LDR sensor), while the solar tracking microcontroller analysis section is the ADC analysis (PWM motor analysis for servo motor rotation angle). If appropriate the research will be continued. If not, data retrieval will be performed again.

\section{Research Methods}

\subsection{System Design}

Fig.1 shows a block diagram of the system that has been created. Arduino Mega as the brain receives and sends commands in the form of input and output to the driver to control equipment such as LDR sensors, DC voltage sensors and servo motors. so that it operates as desired. LDR sensor will detect the direction of the sun which produces an output voltage with a range of 1-5 Volt DC, which will be converted by Arduino Mega into digital bits. LDR sensor uses 4 sensors where one of the sensors will produce an output voltage close to 5 Volt $\mathrm{DC}$, the tracker will lead to the position of the sensor which has an output voltage and close to 5 Volt DC voltage. While the DC voltage sensor will detect the output voltage of the Solar cell which produces an output voltage in the range of 1-5 Volts DC, which will be converted by Arduino Mega into digital bits.

Draw a block diagram of this research system as follows: 


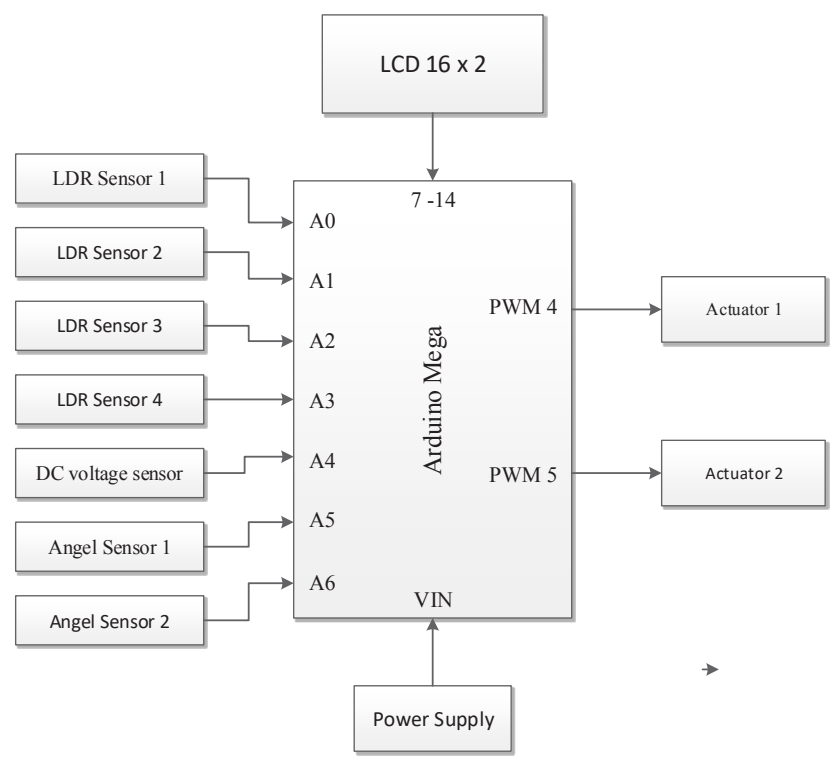

Fig. 1. Tool design block diagram

From the LDR sensor conversion results in an output voltage close to 5 Volt DC it will give a command in the form of a PWM (Pulse-width modulation) output which will provide an angle position with a range of $0-1800$ on the servo motor.

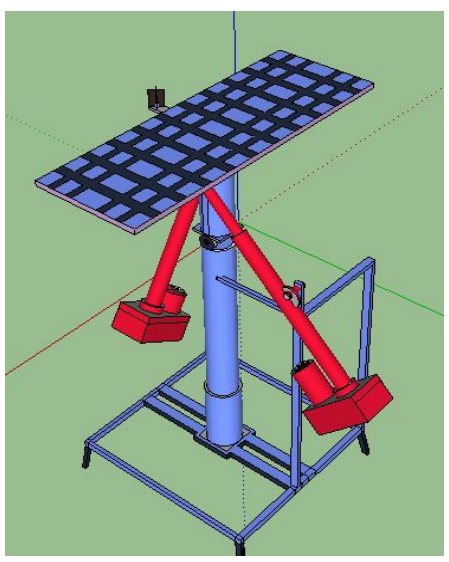

Fig. 2. Solar Tracker Design

The design consists of the top, middle and bottom. The upper part is where the solar cell is supported by an aluminum frame and is equipped with a Motor Actuator as a driver for a single rotary axis. The middle part of the tool only support that is equipped by a motor so that the middle part also functions as the second rotary axis. The bottom is the base of the base tool.

\subsection{Stage of research}

In this research, monocstalline type photovoitaic is used, Merk Shinyoku, serial number of 20-997, Irradiance of $1000 \mathrm{~W} / \mathrm{m}^{2}$, dimensiom of 1210 x 808 x 28 mm, Maximum Power (PM) 
of $80 \mathrm{~W}$, Maximum Power Voltage (Vmp) of 17,6 V, Maximum Power Current (Imp) of 4.55 A, Open Circuit Voltage (Voc) of 21,8 V and Short Circuit Current (Isc) of 5,23 A.

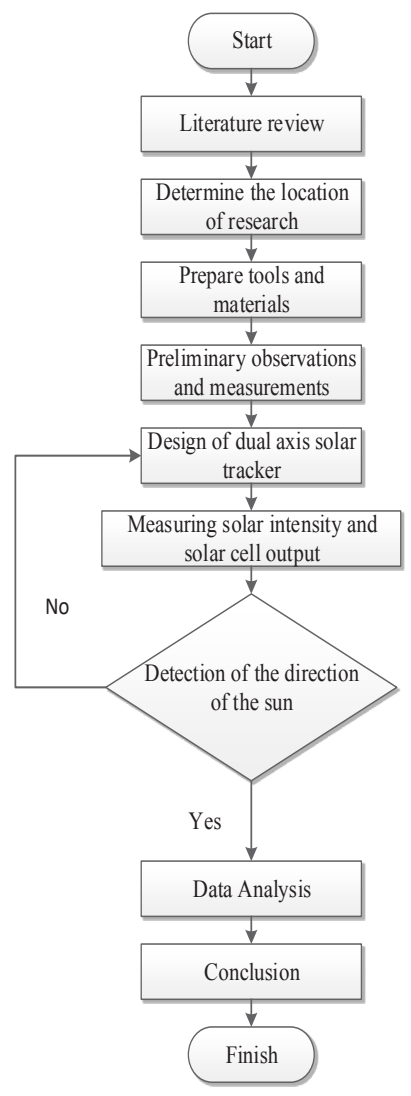

Fig. 3. Stage of research

\section{Results and discussion}

\subsection{Retrieval of data}

The results of designing a Solar Tracker System are shown in Figure 4 below:

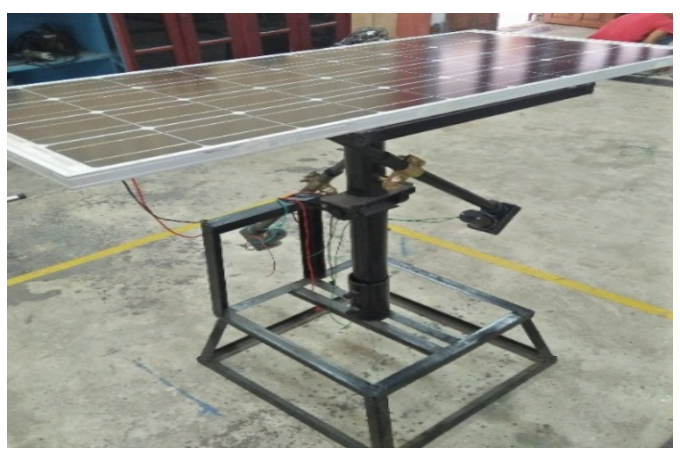

Fig.4. Solar Tracker System 
Figure 4 is a physical form of the Solar Tracker System module that has been designed and manufactured, the function of this module is as monitoring and controller of the Solar Tracker System, the input system is a DC Voltage sensor, angle sensor, light sensor, H-Bridge driver and DC motor accelerator. The function of a solar tracker system is to optimize the absorption of solar energy in the solar cell.

Table 1. Results of measurements of light intensity at the light sensor output voltage

\begin{tabular}{|c|c|c|c|c|c|}
\hline \multirow{2}{*}{ No. } & \multirow{2}{*}{$\begin{array}{c}\text { Light } \\
\text { intensity } \\
(\mathrm{W} / \mathrm{m} 2)\end{array}$} & \multicolumn{4}{|c|}{ Solar Tracker System Module } \\
\hline & & $\begin{array}{l}\text { light sensor1 } \\
\text { ( VDC) }\end{array}$ & $\begin{array}{c}\text { light sensor } 2 \\
\quad \text { ( VDC) }\end{array}$ & $\begin{array}{l}\text { light sensor } 3 \\
\text { (VDC) }\end{array}$ & $\begin{array}{c}\text { light sensor } 4 \\
\text { (VDC) }\end{array}$ \\
\hline 1. & 0 & 0 & 0 & 0 & 0 \\
\hline 2. & 76 & 0,38 & 0,38 & 0,38 & 0,38 \\
\hline 3. & 152 & 0,77 & 0,77 & 0,77 & 0,77 \\
\hline 4. & 228 & 1,15 & 1,15 & 1,15 & 1,15 \\
\hline 5. & 305 & 1,53 & 1,53 & 1,53 & 1,53 \\
\hline 6. & 381 & 1,92 & 1,92 & 1,92 & 1,92 \\
\hline 7. & 457 & 2,31 & 2,31 & 2,31 & 2,31 \\
\hline 8. & 533 & 2,69 & 2,69 & 2,69 & 2,69 \\
\hline 9. & 610 & 3,07 & 3,07 & 3,07 & 3,07 \\
\hline 10. & 686 & 3,46 & 3,46 & 3,46 & 3,46 \\
\hline 11. & 762 & 3,84 & 3,84 & 3,84 & 3,84 \\
\hline 12. & 839 & 4,23 & 4,23 & 4,23 & 4,23 \\
\hline 13. & 915 & 4,61 & 4,61 & 4,61 & 4,61 \\
\hline 14. & 991 & 5,00 & 5,00 & 5,00 & 5,00 \\
\hline
\end{tabular}

Table 1. above shows the results of measurements of the intensity of sunlight at the light sensor voltage, this measurement proves that the results of the measurement of the light sensor voltage are directly proportional to the measurement of sunlight intensity. The voltage on the light sensor will be processed by the ADC (Analog to Digital Converter) on Arduino Mega used as a detector of sunlight, where the ADC input voltage rating is 0 - 5 VDC which will be compared as the movement of the Solar Tracker System.

Table 2. shows the results of measurements in the Solar Tracker System process carried out by sampling data from 09.00 to 16.00 . The table above also proves that the output voltage is influenced by the intensity of sunlight and the tilt angle of the solar cell. The angle of the Solar System Tracker has two axes namely the $\mathrm{X}$-axis and the $\mathrm{Y}$-axis. The $\mathrm{X}$-axis has a slope angle rating of -400 to 400 , a negative angle value (-) means the solar panel is tilted to the East while the positive angle value $(+)$ of the solar panel is tilted to the west. While the angle of the $\mathrm{Y}$-axis has a rating of -250 to 250 , a negative angle value (-) means that the solar panel is tilted to the south while the positive angle value $(+)$ means the solar panel is tilted towards the north.

Table 2. Measurement results on the Solar Tracker System process

\begin{tabular}{|c|c|c|c|c|c|c|}
\hline \multirow[b]{2}{*}{ No. } & \multirow{2}{*}{$\begin{array}{c}\text { Time } \\
\text { (hour) }\end{array}$} & \multirow{2}{*}{$\begin{array}{c}\text { Light } \\
\text { intensity } \\
\left(\mathbf{W} / \mathbf{m}^{2}\right)\end{array}$} & \multirow{2}{*}{$\begin{array}{c}\text { The angle of } \\
\text { the Solar Cell } \\
\text { Against } \\
\text { sunlight } \\
(\circ)\end{array}$} & \multicolumn{3}{|c|}{ Modul Sistem Solar Tracker } \\
\hline & & & & $\begin{array}{c}\text { Angle } 1 \\
\left({ }^{\circ}\right)\end{array}$ & $\begin{array}{c}\text { Angle } 1 \\
\left({ }^{\circ}\right)\end{array}$ & $\begin{array}{l}\text { Output } \\
\text { voltage } \\
\text { (VDC) }\end{array}$ \\
\hline 1. & 09.00 & 610 & 87,36 & 12 & -40 & 18,6 \\
\hline 2. & 10.00 & 839 & 86,05 & 9 & -30 & 18,0 \\
\hline
\end{tabular}




\begin{tabular}{|l|l|l|l|l|l|l|}
\hline 3. & 11.00 & 915 & 82,14 & 7 & -16 & 18,5 \\
\hline 4. & 12.00 & 991 & 84,74 & 5 & -2 & 18,6 \\
\hline 5. & 13.00 & 991 & 86,71 & 4 & 10 & 18,5 \\
\hline 6. & 14.00 & 839 & 82,14 & 2 & 25 & 18,6 \\
\hline 7. & 15.00 & 610 & 80,85 & 1 & 40 & 18,4 \\
\hline 8. & 16.00 & 381 & 80,85 & 1 & 40 & 18,5 \\
\hline
\end{tabular}

The inclination angle of each sample varies with the movement of the sun and will return to position $0 \mathrm{o}$ when the intensity of sunlight is $0 \mathrm{~W} / \mathrm{m} 2$. This means that changes in sunlight intensity greatly affect the movement of the position of each tilt of the Solar Tracker System.

Table 3. Solar cell tracking system comparison and not tracking

\begin{tabular}{|c|c|c|c|c|c|c|}
\hline \multirow{2}{*}{ No. } & \multirow{2}{*}{ Time } & \multirow{2}{*}{$\begin{array}{c}\text { Light } \\
\text { intensity } \\
\left(\mathbf{W} / \mathbf{m}^{2}\right)\end{array}$} & $\begin{array}{c}|c| \\
\text { Tracking } \\
\text { Panel }\end{array}$ & $\begin{array}{c}\text { No Tracking } \\
\text { Panel }\end{array}$ & $\begin{array}{c}\text { Tracking } \\
\text { Panel }\end{array}$ & $\begin{array}{c}\text { No Tracking } \\
\text { Panel }\end{array}$ \\
\hline 1. & 09.00 & 417 & 18,81 & 18,56 & 3,05 & 2,52 \\
\hline 2. & 10.00 & 626 & 18,56 & 18,39 & 3,91 & 3,54 \\
\hline 3. & 11.00 & 737 & 18,32 & 18,23 & 4,22 & 4,06 \\
\hline 4. & 12.00 & 740 & 18,32 & 18,24 & 4,27 & 4,19 \\
\hline 5. & 13.00 & 642 & 18,41 & 18,37 & 3,88 & 3,65 \\
\hline 6. & 14.00 & 603 & 18,45 & 18,38 & 3,74 & 3,18 \\
\hline 7. & 15.00 & 464 & 18,62 & 18,47 & 3,43 & 2,25 \\
\hline 8. & 16.00 & 215 & 18,20 & 18,02 & 2,11 & 1,20 \\
\hline
\end{tabular}

From the results of measurements of voltage and current in solar cell tracking and solar cell without tracking prove that the effectiveness of solar cell tracking is a bit more efficient when compared to solar cells without tracking, it can be seen from 09.00 to 12.00 to 16.00 comparison of voltage on solar cell tracking more greater than the voltage of the solar cell without tracking, as well as the comparison of the currents in the solar cell tracking and without tracking from 09.00 to 12.00 to 16.00 the current generated from the solar cell tracking is slightly greater than the solar cell without tracking.

This also proves that the temperature can affect the voltage on the solar cell, if the temperature of the solar cell rises from the reference temperature given, the resulting voltage will decrease. Another case with the current produced, where the current in the solar cell is influenced by the intensity of light, if the intensity of the light rises, the current also rises, because the current and light intensity are directly proportional.

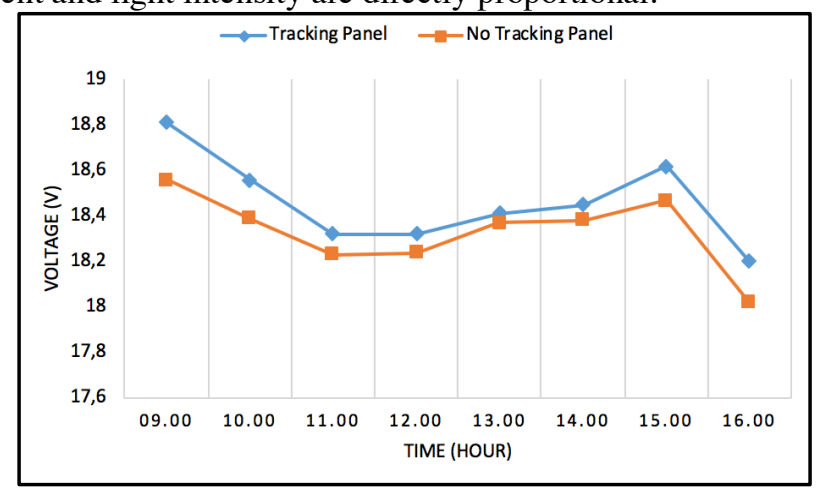

Fig. 5. Comparison of solar cell tracking voltage and solar cell without tracking concerning for to time 


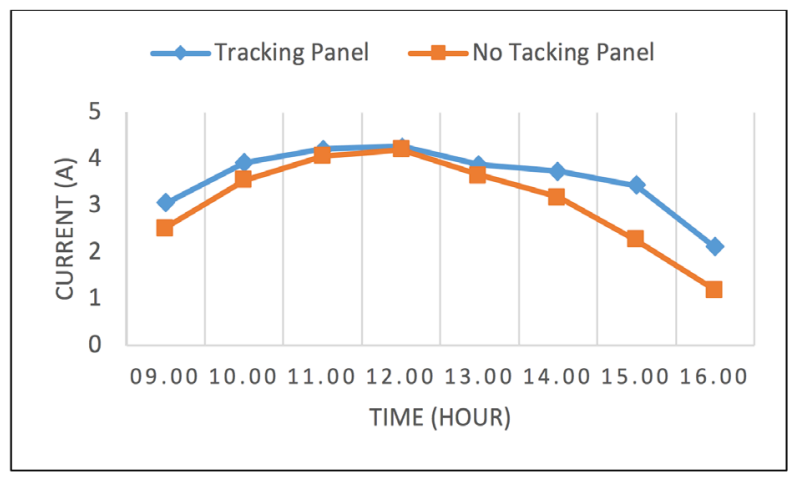

Fig. 6. Comparison of solar cell tracking currents and solar cells without tracking concerning for to time

\subsection{Calculation of Formed Shadow Angle}

This calculation is carried out to determine the value of the angle of the shadow formed at the position of the sun against the slope of the solar panel, the height of the pole from the shadow measuring instrument is $4.35 \mathrm{~cm}$ and utilizing the length of the shadow formed, the results of the shadow angle formed with reference Tan $\theta=(x) /(y)$, So you can see the calculation below as follows:

The length of the shadow formed $=0.2 \mathrm{~cm}$

Tan $\theta=$ (shadow height gauge) / (Length of shadow formed)

$\operatorname{Tan} \theta=(4.35 \mathrm{~cm}) /(0.2 \mathrm{~cm})=21.750=87.360$

The length of the shadow formed $=0.7 \mathrm{~cm}$

Tan $\theta=$ (shadow height gauge) / (Length of shadow formed)

Tan $\theta=(4.35 \mathrm{~cm}) /(0.7 \mathrm{~cm})=6.210=80.850$

From the above calculation, it can be seen the angle of the shadow formed from sunlight to the slope of the solar cell, if the value of the angle of the shadow that is formed is close to 900 then the length of the image formed is getting smaller. While the value of the angle of the shadow that is formed is approaching 00 then the length of the shadow formed is greater.

\section{Conclusion}

Based on the results of the design and analysis of the data obtained, it can be concluded that the LDR sensor as a detector of sunlight becomes the Arduino Mega input which functions as the control center of the Solar Tracker System with the output of the actuator that moves the solar panel. the position of solar panels that follow the direction of sunlight can maximize the output voltage and current compared to solar panels that are not tracked. The output voltage is also affected by the temperature of the solar panel, if the temperature of the solar cell rises from the reference temperature given then the resulting voltage will decrease. While the current produced is influenced by the intensity of the light, when the intensity of the light rises, the current also rises and when the intensity of the sun's light falls, the output current of the solar panel goes down. 


\section{References}

1. O. Edenhofer, et al. Renewable energy sources and climate change mitigation: Special report of the intergovernmental panel on climate change (2011)

2. P. Owusu, S.Sarkodie, Cogent oa,3: 1167990 (2016)

3. W. Moomaw, et al, IPPC, Renewabe Energy and Climate Change (2011)

4. S. Teske, K. Nagrath, T. Morris, K. Dooley, Achieving the Paris Climate Agreement Goal, 161-173 (2019)

5. Plans for the long-term development of the Palu city area in 2005-2025

6. S. Rajput, Solar energy- Fundamentals, Economic and Energy Analysis Book, 2 (2017)

7. C.R.Algarin et al., Int. Journal Of Renewable Energy Research, Vol.7, No.1, (2017)

8. A. Ponniran, A. Hashim, H. Ali Munir, PEOCO2011, 107 (2011)

9. S. Amely Jumaat, A. Tan, M. Noor Abdullah, N. Hanis Radzi,R. Hamdan, S. Salimin, M.Nafis bin Ismail, Indonesian Journal of Electrical Engineering and Computer Science, Vol. 12, No. 2, 489-496 (2018)

10. S. Kamble, S. Kamble, V. Chavan, A. Mestry, N. Patil, IJIERT, Vol. 2 (2015) 